\title{
Identificação de plântulas zigóticas de trifoliata com o uso de marcadores moleculares RAPD
}

\author{
Gilmar Schäfer ${ }^{(1)}$, Marinês Bastianel(2) e Ana Lúcia Cunha Dornelles ${ }^{(3)}$
}

\begin{abstract}
(1)Universidade Federal do Rio Grande do Sul (UFRGS), Fac. de Agronomia, Av. Bento Gonçalves, 7712, CEP 91501-970, Porto Alegre, RS. E-mail: gilmarschafer@hotmail.com (2)Universidade Estadual de Campinas, Caixa Postal 6109, CEP 13083-970 Campinas, SP. E-mail: mbastianel@yahoo.com (3)UFRGS, Dep. de Horticultura e Silvicultura. E-mail: alcunha@vortex.ufrgs.br
\end{abstract}

\begin{abstract}
Resumo - O objetivo deste trabalho foi identificar a frequiência de germinação dos embriões zigóticos de sementes de trifoliata [Poncirus trifoliata (L.) Raf.] oriundas de polinização aberta, com o uso de marcador molecular RAPD. Folhas e sementes de trifoliata foram coletadas de cinco viveiros comerciais e de uma coleção experimental de citros. Essas sementes foram colocadas para germinar em tubetes e casa de vegetação, totalizando uma amostra final de 62 plântulas. Foram utilizadas nove sequiências inicializadoras e os resultados foram analisados a partir da comparação dos padrões das bandas geradas pelas plantas germinadas com os da planta matriz. Identificaram-se 3,23\% de plântulas oriundas da germinação do embrião zigótico, valor que é aceitável na propagação por sementes deste porta-enxerto cítrico.
\end{abstract}

Termos para indexação: Poncirus trifoliata, porta-enxerto, citros, embrião.

\section{Identification of zygotic trifoliate orange seedlings with RAPD molecular markers}

\begin{abstract}
This work aimed to determine germination frequency of zygotic embryos of seeds originated from open pollinated trifoliate orange [Poncirus trifoliata (L.) Raf.], using RAPD molecular markers. Leaves and seeds of $P$. trifoliata were collected from five commercial nurseries and from a citrus germplasm collection. The seeds were placed to germinate in plastic tubes in a greenhouse, reaching a final sample of 62 seedlings. Nine primers were used and the band patterns generated from seedlings leaves were compared to progenitor-plantleaf hands. It was possible to identify $3.23 \%$ of seedlings originated from zygotic embryos which is acceptable in propagation by seeds in this rootstock.
\end{abstract}

Index terms: Poncirus trifoliata, rootstocks, citrus, embryo.

\section{Introdução}

De modo geral, as sementes de citros são poliembriônicas, ou seja, possuem dois ou mais embriões. Normalmente um embrião é zigótico, resultante da fecundação, e os demais são produzidos assexualmente por divisões mitóticas de células somáticas do nucelo e, por isso, são chamados de embriões nucelares (Frost \& Soost, 1968; Koltunow, 1993; Koller, 1994).

No campo, os embriões nucelares apresentam maior vigor, dominando os embriões resultantes da fecundação, cujas plântulas raramente desenvolvem-se (Koller, 1994). Esse autor relata que tal fato proporciona um elevado índice de mudas oriundas de clones nucelares com características idênticas as da planta matriz; por isso os porta-enxertos de citros podem ser obtidos através de sementes, sem segregação genética, mantendo as características desejadas. Entretanto, segundo Frost \& Soost (1968), quando a competição entre plantas é menor, no caso de cultivo em bandejas multicelulares ou tubetes, a frequiência de germinação e sobrevivência do embrião zigótico pode ser alterada, dependendo da sua localização e da proporção relativa dos embriões nucelares, bem como da fase em que se inicia seu desenvolvimento e do seu vigor genético.

A diferenciação da plântula desenvolvida a partir da germinação do embrião zigótico ou nucelar pode ser feita por meio de características morfológicas, tais como: formato da folha, pecíolo. O porta-enxerto mais utilizado no Rio Grande do Sul, Poncirus trifoliata (L.) Raf. (Schäfer \& Dornelles, 2000), apresenta o caráter trifoliolado dominante sobre o monofoliolado (Cameron \& Frost, 1968), o que dificulta a identificação morfológica das plântulas zigóticas, porque seus híbridos são idênticos.

$\mathrm{O}$ uso de marcadores bioquímicos, principalmente análise isoenzimática, é uma das técnicas mais utilizadas para distinguir os embriões zigóticos dos nucelares (Aschari et al., 1989). Em trabalhos realizados para dife- 
renciar plântulas zigóticas de nucelares, por análise isoenzimática, identificou-se freqüência de mudas zigóticas, em populações de várias cultivares de portaenxertos, menor que $10 \%$ em laranjas doce, citranges 'Carrizo', 'Troyer' e 'Uvalde', mandarina 'Cleópatra', Citrus amblycarpa, laranja 'Azeda' e 'Milam' e limão rugoso (Moore \& Castle, 1988; Roose, 1988). Frequiências mais altas foram encontradas em Citrus taiwanica, limoeiro 'Yuma Ponderosa', shaddock Cuban, limoeiro 'Volkameriano', citrange 'Yuma', citrumelos 'Sacaton' e 'Swingle', e alguns genótipos de Poncirus trifoliata (Khan \& Roose, 1988; Moore \& Castle, 1988; Roose, 1988). A freqüência de plântulas zigóticas em sementes de polinização aberta de Poncirus trifoliata 'Flying Dragon' variou de $11 \%$ a 48\% (Khan \& Roose, 1988; Roose, 1988).

A técnica de amplificação de sequiência de DNA permite a comparação direta dos alelos, por meio da composição em nucleotídeos da seqüência. Este método, denominado de PCR (Reação em Cadeia da Polimerase), permite a comparação molecular dos organismos, sem influência do ambiente ou idade do tecido amostrado (Bered et al., 1997; Morell et al., 1995), enquanto a composição isoenzimática de organismos varia com esses fatores, dificultando sua análise (Asins et al., 1995). Entre as técnicas derivadas da PCR, utilizadas na análise da diversidade genética, o RAPD (Polimorfismo de DNA amplificado ao acaso) utiliza primers ao acaso com cerca de $10 \mathrm{pb}$; sempre que o genoma do indivíduo a ser analisado apresentar uma seqüência de nucleotídeos correspondente ao do primer, o processo de amplificação é iniciado; a identificação do DNA é inferida pela presença ou ausência de determinados fragmentos amplificados (Morell et al., 1995; Bered et al., 1997).

$\mathrm{O}$ objetivo deste trabalho foi identificar a freqüência de germinação do embrião zigótico, a partir de sementes oriundas de polinização aberta de Poncirus trifoliata (L.) Raf., utilizando o marcador molecular RAPD.

\section{Material e Métodos}

O material vegetal utilizado foi obtido em 1999, na coleção de citros da Estação Experimental Agronômica da Universidade Federal do Rio Grande do Sul (EEA/ UFRGS), localizada no Município de Eldorado do Sul e em cinco bancos de sementes de viveiros de Pareci Novo e Taquari, da região do Vale do Rio Caí, RS.

De uma planta de cada local amostrado, foram coletadas folhas jovens e frutos maduros, dos quais fo- ram extraídas 20 sementes de cada acesso, que foram colocadas para germinar em tubetes de plástico de $50 \mathrm{~cm}^{3}$, contendo casca de arroz carbonizada, solo Podzólico Vermelho-Escuro horizonte B e esterco de gado curtido, na proporção de 3:1:1 (v:v:v), em casa de vegetação.

A extração do DNA total das plantas matrizes foi feita logo após a coleta das folhas no campo; das sementes germinadas, quando alcançaram cinco a seis folhas e cerca de $12 \mathrm{~cm}$ de altura, foram escolhidas, aleatoriamente, 62 plântulas para a extração do DNA total. Nas sementes que originaram duas plântulas, o DNA foi extraído separadamente.

A extração do DNA genômico foi realizada segundo Murray \& Thompson (1980), com algumas modificações sugeridas por Machado et al. (1996). As folhas foram trituradas em $\mathrm{N}$ líquido, até a obtenção de um pó bem fino, colocado em tubos Eppendorfs de 1,6 mL, homogeneizado com $0,8 \mathrm{~mL}$ de tampão de extração $(5 \%$ CTAB, 100 mM Tris-HCl pH 7,5; 10 mM EDTA, 0,7 M $\mathrm{NaCl}, 5 \%$ sarcosyl, $140 \mathrm{mM}$ 2-mercaptoetanol) e aquecido a $60^{\circ} \mathrm{C}$ por 30 minutos em banho-maria. Após resfriar até a temperatura ambiente, foi realizada extração com um volume de clorofórmio:álcool isoamílico (24:1). A seguir, a solução foi misturada em um agitador para tubos e centrifugada por oito minutos a $13.400 \mathrm{~g}$. O sobrenadante foi transferido para outro tubo Eppendorf, no qual adicionou-se 0,1 volume de CTAB $10 \%$ (10\% CTAB e $0,7 \mathrm{M} \mathrm{NaCl})$ e realizou-se uma nova extração com um volume de clorofórmio:álcool isoamílico (24:1).

Na precipitação do DNA, a fase sobrenadante foi transferida para um novo tubo, adicionando-se um volume de tampão de precipitação ( $1 \%$ CTAB, $50 \mathrm{mM}$ Tris$\mathrm{HCl} \mathrm{pH}$ 8,0, 10 mM EDTA). Após misturar vagarosamente, os tubos foram centrifugados por cinco minutos a $9.300 \mathrm{~g}$ e a fase sobrenadante, descartada. O pélete obtido foi dissolvido em $400 \mu \mathrm{L}$ de tampão salino de extração (TE) (10 mM tris-HCl pH 8,0, 1 mM EDTA, $1 \mathrm{M} \mathrm{NaCl})$ em banho-maria $\left(65^{\circ} \mathrm{C}\right)$ até total dissolução. Quando os tubos atingiram a temperatura ambiente, o DNA foi precipitado com dois volumes de etanol absoluto gelado e centrifugado por cinco minutos a $13.400 \mathrm{~g}$. O sobrenadante foi descartado e os sedimentos, lavados com etanol $70 \%$ e $100 \%$. O DNA foi dissolvido em $25 \mu \mathrm{L}$ de $1 / 10$ de TE contendo $10 \mu \mathrm{g} / \mathrm{mL}$ de RNAse. O DNA extraído foi conservado em congelador $\left(-20^{\circ} \mathrm{C}\right)$ até a sua utilização. 
A quantificação e qualificação do DNA genômico foi efetuada segundo Sambrook et al. (1989), utilizando-se $1 \mu \mathrm{L}$ de cada amostra de DNA, misturados com $3 \mu \mathrm{L}$ de água mili Q autoclavada e $1 \mu \mathrm{L}$ de tampão da amostra $(0,25 \%$ de azul de bromofenol e $40 \%$ de sacarose), colocados em gel de agarose a $0,8 \%$, corados com brometo de etídeo $(0,5 \mathrm{ng} / \mathrm{mL})$ e comparadas com uma série de diluições do marcador molecular $\lambda$ DNA com concentrações conhecidas $(25,50,100,150,200 \mathrm{e}$ $300 \mathrm{ng} / \mu \mathrm{L}$ ). Após 30 minutos de corrida eletroforética, o gel foi observado sob luz ultravioleta e a intensidade de fluorescência das amostras de DNA, comparada com os padrões. A seguir, uma alíquota de cada amostra de DNA foi diluída a uma concentração de trabalho de $5 \mathrm{ng} / \mu \mathrm{L}$ e armazenada em congelador.

As reações de amplificação foram preparadas em um volume de $12,3 \mu \mathrm{L}$ contendo duas unidades da enzima Taq DNA polimerase (Cenbiot/RS), $1 \mu \mathrm{L}$ de dNTPs - $200 \mathrm{mM}$ de cada (dATP, dTTP, dCTP e dGTP), $1,3 \mu \mathrm{L}$ de tampão $10 \mathrm{X}$ (100 mM Tris-HCl $\mathrm{pH} 8,3$, $500 \mathrm{mM} \mathrm{KCl}, 2,0 \mathrm{mM}$ de $\mathrm{MgCl}_{2}$ e $0,01 \%$ de gelatina), $3 \mu \mathrm{L}(15 \mathrm{ng})$ de sequiências inicializadoras, com um número de 8 e 10 nucleotídeos (Tabela 1), $2 \mu \mathrm{L}$ da solução de DNA (10 ng) e o restante de água mili Q autoclavada. As reações foram preparadas em tubos de $0,5 \mathrm{~mL}$, nos quais o DNA foi colocado no fundo e, por cima, 10,3 $\mu \mathrm{L}$ da mistura contendo os componentes da reação. Para evitar a evaporação durante o ciclo PCR, foram adicionados $10 \mu \mathrm{L}$ de óleo mineral. A amplificação foi realizada em um termociclador, programado para 36 ciclos de um minuto a $92^{\circ} \mathrm{C}$, um minuto a $36^{\circ} \mathrm{C}$ e dois minutos a $72^{\circ} \mathrm{C}$, acrescidos de 10 minutos a $72^{\circ} \mathrm{C}$ ao final do último ciclo.
A seleção das seqüências inicializadoras foi feita segundo resultados obtidos por outros autores, ou seja, foram utilizadas algumas das seqüências que já haviam sido utilizadas com sucesso em citros (Tabela 1).

Os padrões de amplificação foram visualizados mediante eletroforese em gel de agarose $1,4 \%$, preparado com tampão TAE $1 \mathrm{X}(0,04 \mathrm{M}$ Tris acetato e $1 \mathrm{mM}$ de EDTA) e corados com brometo de etídeo. A cada amostra, foram adicionados $2,2 \mu \mathrm{L}$ de tampão da amostra ( $0,25 \%$ de azul de bromofenol e $40 \%$ de sacarose) e, em cada canaleta do gel aplicou-se $6 \mu \mathrm{L}$ da amostra. Marcadores de peso molecular conhecido (DNA Ladder $1 \mathrm{~Kb}$-Gibco) foram colocados nas extremidades do gel como padrão para determinar o tamanho dos fragmentos gerados pela técnica RAPD. A corrida eletroforética foi realizada a 100 volts, à temperatura ambiente, em tampão TAE $1 \mathrm{X}$ por aproximadamente três horas. Os géis foram fotografados utilizando luz ultravioleta.

A análise dos dados moleculares, para a determinação do porcentual de plantas zigóticas, foi realizada comparando-se os padrões de bandas gerados pelas plantas germinadas aos das bandas da planta matriz.

\section{Resultados e Discussão}

O número de fragmentos amplificados, considerando-se a utilização de nove oligonucleotídeos iniciadores, variou de três a cinco, e o porcentual de plântulas obtidos a partir da germinação do embrião zigótico foi de 3,23 (Tabela 1).

A detecção do embrião zigótico ocorreu por meio da ausência de produtos de amplificação materna (Figura 1, coluna 3). Os híbridos foram detectados através

Tabela 1. Relação das seqüências inicializadoras utilizadas na determinação do porcentual de germinação do embrião zigótico em Poncirus trifoliata com suas citações e o número de fragmentos amplificados e polimórficos.

\begin{tabular}{|c|c|c|c|c|}
\hline \multirow{2}{*}{$\begin{array}{c}\text { Seqüência } \\
\text { inicializadora }\end{array}$} & \multirow[t]{2}{*}{ Seqüência } & \multirow[t]{2}{*}{ Citação } & \multicolumn{2}{|c|}{ Número de fragmentos } \\
\hline & & & Amplificados & Polimórficos \\
\hline $\mathrm{P} 130$ & 5' CGCGGCCA 3' & Targon et al. (1998) & 5 & 0 \\
\hline OPH15 & 5' AATGGCGCAG 3' & Bastianel et al. (1998) & 3 & 0 \\
\hline OPM05 & 5' GGGAACGTGT 3' & Cristofani (1997) & 2 & 0 \\
\hline OPA05 & 5' AGGGGTCTTG 3', & Cai et al. (1994) & 5 & 0 \\
\hline OPA09 & 5' GGGTAACGCC 3', & Cai et al. (1994) & 3 & 1 \\
\hline OPN14 & 5' TCGTGCGGGT 3', & Cristofani (1997) & 3 & 1 \\
\hline ОРT08 & 5' AACGGCGACA 3', & Cai et al. (1994) & 5 & 0 \\
\hline OPA04 & 5' AATCGGGCTG 3', & Cai et al. (1994) & 4 & 0 \\
\hline OPH04 & 5' GGAAGTCGCC 3, & Bastianel (1999) & 5 & 0 \\
\hline Total & & & 35 & 2 \\
\hline \multicolumn{3}{|c|}{ Germinação do embrião zigótico (\%) } & & 3,23 \\
\hline
\end{tabular}


da identificação de alelos dominantes perdidos pela genitora em eventos de recombinação, possivelmente na autofecundação. A fecundação cruzada, com um genitor que não possua locus dominantes homozigotos, não pode ser descartada, entretanto, esta hipótese é pouco provável pelo fato do P. trifoliata florescer precocemente, nas condições do Rio Grande do Sul, em uma época de pouca disponibilidade de pólen de outras espécies e cultivares, mesmo nas condições de coleção de germoplasma deste trabalho.

O método RAPD, como marcador de natureza dominante, não discrimina adequadamente a ocorrência de heteromorfismos intralocos (Tingey \& Del Tufo, 1993; Weeden et al., 1992, citado por Silva, 1996). Todavia, a discriminação entre materiais muito aparentados com o uso de marcadores RAPD pode ser alcançada quando se aumenta o número de bandas polimórficas, por meio do uso de um maior número de oligonucleotídeos inicializadores (Jain et al., 1994; Ferreira \& Grattaplaglia, 1995) ou do uso de outros marcadores moleculares não dominantes, como microssatélites (Thomas et al., 1998; Bastianel, 1999).

As sementes originaram plantas com vigor semelhante, com exceção de cinco sementes que originaram duas plantas, em que uma delas era menor. Entretanto, as

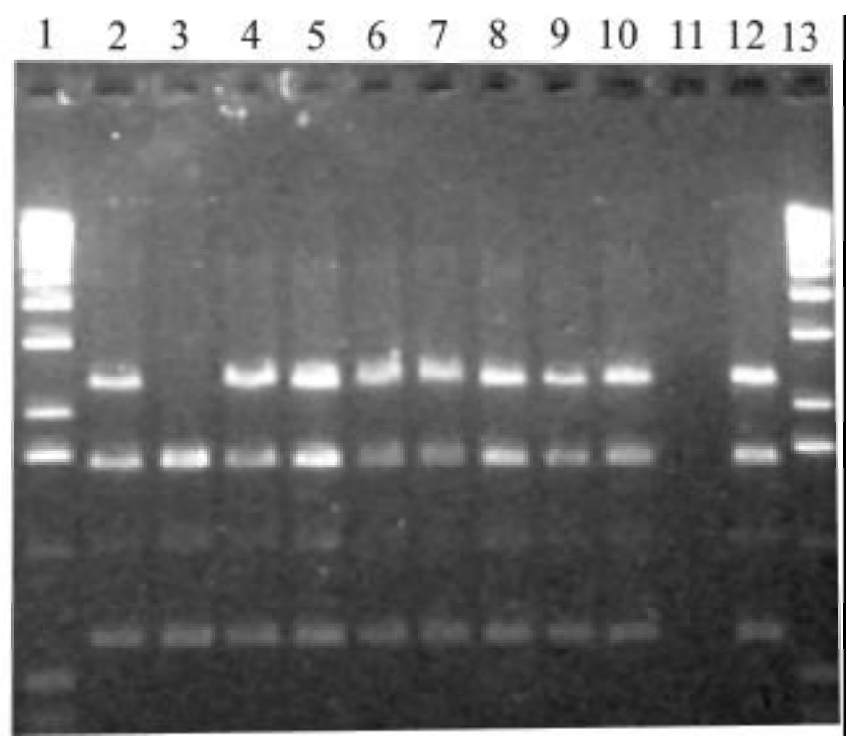

Figura 1. Produtos de amplificação com o oligonucleotídeo iniciador OPA09, na identificação de plântulas zigóticas de Poncirus trifoliata; a primeira e última coluna: marcador $1 \mathrm{~Kb}$ Ladder; segunda coluna, genitora; colunas 3 a 12, geração $F_{1}$ de polinização aberta; na coluna 3 encontra-se uma planta híbrida. plantas separadas como zigóticas foram originadas de sementes que germinaram uma só planta. Segundo Cristofani \& Machado (1998), numa população de viveiro que não sofreu seleção, freqüentemente mais de uma planta aparece por semente e, a menor das duas é, em geral, a zigótica. Essa informação não pode ser confirmada pelos dados obtidos, pois as plantas zigóticas detectadas não foram as que apresentaram germinação de mais de uma planta por semente. Khan \& Roose (1988), na determinação da frequiência e da característica de plântulas zigóticas de $P$. trifoliata (L.) Raf., obtiveram de $0 \%$ a $76 \%$ de germinação do embrião zigótico, dependendo do ano e da cultivar. Esses autores chegaram à conclusão de que, morfologicamente, muitas plantas zigóticas eram tão semelhantes às nucelares - em altura, tamanho de folha, comprimento de espinho, comprimento do pecíolo e diâmetro do caule - que seria difícil identificá-las por estas características.

Dados similares de germinação do embrião zigótico foram encontrados por Cristofani \& Machado (1998), que utilizaram marcadores RAPD e obtiveram em torno de 6\% de plantas zigóticas em limoeiro 'Cravo', que já haviam passado pela seleção visual no viveiro. Por sua vez, Anderson et al. (1991), utilizando isoenzimas em citrumeleiro 'Swingle', encontraram até $13,4 \%$ de plantas zigóticas, em sementes que produziram uma planta, 5,07\% em sementes que produziram duas plantas e $5,13 \%$ em sementes que produziram três plantas, com uma média de 9,30\%. Roose \& Traught (1988) e Fatta del Bosco et al. (1994) também encontraram porcentual de germinação do embrião zigótico superior ao deste estudo.

A taxa de 3,23\% de híbridos germinados a partir de sementes de $P$. trifoliata pode ser considerada baixa, quando observa-se essa forma de propagação na produção de porta-enxertos, em viveiros comerciais, ou seja, a utilização de porta-enxertos a partir de sementes, na produção de mudas cítricas, pode ser considerada uma prática adequada. Porém, é inaceitável para produção de plantas matrizes em que a preocupação reside nos bancos de sementes dos viveiristas, que devem ser compostos por plantas de origem genética garantida, a fim de evitar a ocorrência de segregação entre elas. Como consequiência da utilização de plantas híbridas como porta-enxertos, pode-se ter uma segregação de características importantes atribuídas a estes, como é relatado por Anderson et al. (1991), que detectaram, utilizando isoenzimas, 5,2\% de porta-enxertos zigóticos em um pomar de laranjeiras 'Valência' e verificaram que, em 
algumas dessas plantas, havia caneluras na região da enxertia da copa, indicando segregação em relação à tristeza dos citros ou incompatibilidade de enxertia. Soares Filho et al. (1991) também alertam para a possibilidade de milhões de copas cítricas estarem enxertadas sobre híbridos de limoeiro 'Cravo', sugerindo a existência de variabilidade genética capaz de permitir a seleção de novos porta-enxertos ou segregação para características indesejáveis.

\section{Conclusão}

O baixo percentual de plântulas $(3,23 \%)$ provenientes da germinação do embrião zigótico de Poncirus trifoliata (L.) Raf. pode ser considerado um valor aceitável na propagação por sementes deste porta-enxerto cítrico.

\section{Agradecimento}

À Capes e Fapergs, pelo financiamento da pesquisa.

\section{Referências}

ANDERSON, C.M.; CASTLE, W.S.; MOORE, G.A. Isozymic identification of zygotic seedlings in Swingle citrumelo Citrus paradisi $\mathrm{x}$ Poncirus trifoliata nursery and field populations. Journal of the American Society for Horticultural Science, v.116, p.322-326, 1991.

ASCHARI, S.; ASPINALL, D.; SEDGLEY, M. Identification and investigation of relationships of mandarins types using isozyme analysis. Scientia Horticulturae, v.40, p.305-315, 1989.

ASINS, M.J.; HERRERO, R.; NAVARRO, L. Factors affecting citrus tree isozyme-gene expression. Theoretical and Applied Genetics, v.90, p.892-898, 1995.

BASTIANEL, M. Análise de uma população segregante de tangerineira 'Lee' [Citrus reticulata $\mathbf{x}(C$. tangerina $x$ C. paradisi)] através de RAPD e marcadores morfológicos. 1999. 91p. Dissertação (Mestrado) - Universidade Federal do Rio Grande do Sul, Porto Alegre.

BASTIANEL, M.; SCHWARZ, S.F.; COLETA FILHO, H.D.; LIN, L.L.; MACHADO, M.; KOLLER, O.C. Identification of zygotic and nucellar tangerine seedlings (citrus spp.) using RAPD. Genetics and Molecular Biology, v.21, p.123-127, 1998.

BERED, F.; BARBOSA NETO, F.J.; CARVALHO, F.I.F. Marcadores moleculares e sua aplicação no melhoramento genético de plantas. Ciência Rural, v.27, p.513-520, 1997.

CAI, Q.; GUY, C.L.; MOORE, G.A. Extension of the linkage map in Citrus using random amplified polymorphic DNA (RAPD) markers and RFLP mapping of cold-acclimation-responsive loci. Theoretical and Applied Genetics, v.89, p.606-614, 1994.

CAMERON, J.W.; FROST, H.B. Genetics, breeding and nucellar embryony. In: REUTHER, W.; BATCHELOR, L.D.; WEBBER, H.J. (Ed.). The citrus industry. Berkeley: University of California, 1968. v.2, p.325-370.

CRISTOFANI, M. Mapas de ligação de Citrus sunki Hort. ex. Tan. e Poncirus trifoliata (L.) Raf. cv. Rubidoux e localização do gene de resistência ao vírus da tristeza. 1997. 152p. Tese (Doutorado) - Escola Superior de Agricultura Luiz de Queiroz, Piracicaba.

CRISTOFANI, M.; MACHADO, M.A. Utilização de marcadores moleculares na identificação de plântulas zigóticas e nucelares em sementeira de limão 'Cravo'. Laranja, v.19, p.159-166, 1998.

FATTA DEL BOSCO, S.; MATRANGA, G.; GERACI, G. Isozyme analysis of citrus rootstock populations to identify zygotic seedlings. Advances in Horticultural Science, v.8, p.71-74, 1994.

FERREIRA, M.E.; GRATTAPAGLIA, D. Introdução ao uso de marcadores RAPD e RFLP em análise genética. Brasília: EmbrapaCenargen, 1995. 220p.

FROST, H.B.; SOOST, R.K. Seed reproduction: development of gametes and embryos. In: REUTHER, W.; BATCHELOR, L.D.; WEBBER, H.J. (Ed.). The citrus industry. Berkeley: University of California, 1968. v.2, p.290-324.

JAIN, A.; BHATIA, S.; BANGA, S.S.; PRAKASH, S.; LAKSHMIKUMARAN, M. Potential use of random amplified polymorphic DNA (RAPD) technique to study the genetic diversity in Indian mustard (Brassica juncea) and its relationship to heterosis. Theoretical and Applied Genetics, v.88, p.116-122, 1994.

KHAN, I.A.; ROOSE, M.L. Frequency and characteristics of nucellar and zygotic seedlings in three cultivars of trifoliate orange. Journal of the American Society for Horticultural Science, v.113, p.105-110, 1988.

KOLLER, O.C. Citricultura: laranja, limão e tangerina. Porto Alegre: Rigel, 1994. 446p.

KOLTUNOW, A.M. Apomixis: embryo sacs and embryos formed without meiosis or fertilization in ovules. Plant Cell, v.5, p.14251437, 1993.

MACHADO, M.A.; COLETTA FILHO, H.D.; TARGON, M.L.P.N.; POMPEU JÚNIOR, J. Genetic relationship of Mediterranean mandarins (Citrus deliciosa Tenore) using RAPD markers. Euphytica, v.92, p.321-326, 1996.

MOORE, G.A.; CASTLE, W.S. Morphological and isozymic analysis of open-pollinated citrus rootstock populations. Journal of Heredity, v.79, p.59-63, 1988.

MORELL, M.K.; PEAKALL, R.; APPELS, R.; PRESTON,L.R.; LLOYD, H.L. DNA profiling techniques for plant variety identification. Australian Journal of Experimental Agriculture, v.35, p.807-819, 1995.

MURRAY, M.G.; THOMPSON, W.F. Rapid isolation of high molecular weight plant DNA. Nucleic Acids Research, v.8, p.43214325, 1980.

ROOSE, M.L. Isozymes and DNA restriction fragment length polymorphisms in citrus breeding and systematics. In: INTERNA- 
TIONAL CITRUS CONGRESS, 6., Tel Aviv, 1988. Proceedings. Tel Aviv: International Society of Citriculture, 1988. v.1, p.155-165.

ROOSE, M.L.; TRAUGHT, S.N. Identification and performance of citrus trees on nucellar and zygotic rootstocks. Journal of the American Society for Horticultural Science, v.113, p.100-105, 1988.

SAMBROOK, J.; FRITSCH, E.F.; MANIATS, T. Molecular cloning: a laboratory manual. New York: Cold Spring Harbor Laboratory, 1989. v.3.

SCHÄFER, G.; DORNELLES, A.L.C. Produção de mudas cítricas no Rio Grande do Sul: diagnóstico da região produtora. Ciência Rural, v.30, p.587-592, 2000

SILVA, B.A. O uso de marcadores moleculares e descritores morfológicos na caracterização de clones de limão cravo (Citrus limonia Osb.). 1996. 83p. Tese (Doutorado) - Universidade Estadual Paulista, Botucatu.
SOARES FILHO, W.S.; ARAÚJO, J.E.V.; CUNHA, M.A.P.; CUNHA SOBRINHO, A.P.; PASSOS, O.S. Variabilidade genética em limão-cravo. Revista Brasileira de Fruticultura, v.13, p.267272,1991 .

TARGON, M.L.P.N.; MACHADO, M.A.; POMPEU JUNIOR, J. Marcadores 'RAPD' para identificação de plântulas de citrange e citrumelo. Laranja, v.19, p.375-381, 1998.

THOMAS, M.R.; SCOTT, N.S.; BOTTA, R.; KIJAS, J.M.H.; IWAHORI, S.; KANO-MURAKAMI, Y.; SHINKAI, S.; SUGIYAMA, N.; SAKIYAMA, R. Sequence-tagged site markers in grapevine and citrus. Journal of the Japanese Society for Horticultural Science, v.67, p.1189-1192, 1998.

TINGEY, S.V.; DEL TUFO, J.P. Genetic analysis with random amplified polymorphic DNA markers. Plant Physiology, v.101, p.349$352,1993$.

Recebido em 24 de julho de 2003 e aprovado em 26 de novembro de 2003 